\title{
Simultaneous optical, CUTLASS HF radar, and FAST spacecraft observations: signatures of boundary layer processes in the cusp
}

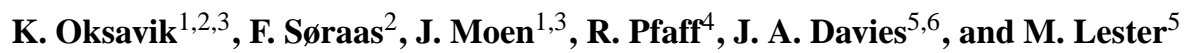 \\ ${ }^{1}$ Department of Physics, University of Oslo, Oslo, Norway \\ ${ }^{2}$ Department of Physics, University of Bergen, Bergen, Norway \\ ${ }^{3}$ Also at Arctic Geophysics, University Centre in Svalbard, Longyearbyen, Norway \\ ${ }^{4}$ NASA/Goddard Space Flight Center, Greenbelt, MD, USA \\ ${ }^{5}$ University of Leicester, Department of Physics and Astronomy, Leicester, UK \\ ${ }^{6}$ Now at Space Science and Technology Department, Rutherford Appleton Laboratory, Chilton, Oxfordshire, UK
}

Received: 31 October 2002 - Revised: 2 July 2003 - Accepted: 11 July 2003 - Published: 1 January 2004

\begin{abstract}
In this paper we discuss counterstreaming electrons, electric field turbulence, HF radar spectral width enhancements, and field-aligned currents in the southward IMF cusp region. Electric field and particle observations from the FAST spacecraft are compared with CUTLASS Finland spectral width enhancements and ground-based optical data from Svalbard during a meridional crossing of the cusp. The observed $630 \mathrm{~nm}$ rayed arc (Type- 1 cusp aurora) is associated with stepped cusp ion signatures. Simultaneous counterstreaming low-energy electrons on open magnetic field lines lead us to propose that such electrons may be an important source for rayed red arcs through pitch angle scattering in collisions with the upper atmosphere. The observed particle precipitation and electric field turbulence are found to be nearly collocated with the equatorward edge of the optical cusp, in a region where CUTLASS Finland also observed enhanced spectral width. The electric field turbulence is observed to extend far poleward of the optical cusp. The broad-band electric field turbulence corresponds to spatial scale lengths down to $5 \mathrm{~m}$. Therefore, we suggest that electric field irregularities are directly responsible for the formation of HF radar backscatter targets and may also explain the observed wide spectra. FAST also encountered two narrow highly structured field-aligned current pairs flowing near the edges of cusp ion steps.
\end{abstract}

Key words. Ionosphere (electric fields and currents). Magnetosphere physics (magnetopause, cusp, and boundary layers; auroral phenomena)

\section{Introduction}

To understand how particles, momentum and energy are transferred from the solar wind to the dayside ionosphere, it is essential to identify the open/closed field line boundary. The crude energy and/or pitch angle distributions offered by low altitude polar orbiting spacecraft have frequently been

Correspondence to: K. Oksavik

(kjellmar.oksavik@fys.uio.no) used to locate this boundary. Different spacecraft specific methods have been developed, depending on which parameters were available. Oksavik et al. (2000) demonstrated this problem, combining two close in time and space satellite passes crossing the cusp aurora. The DMSP F13 spacecraft observed cusp/mantle precipitation, stepped cusp signatures and antisunward convection, suggesting open magnetic field lines. On the other hand, NOAA 12 encountered trapped energetic electrons traditionally regarded as being on closed field lines. This small controversy nicely illustrates one of the major questions of the last 20 years; whether the dayside low-latitude boundary layer (LLBL) is open or closed at the magnetopause.

One signature that has been interpreted both as an indicator of open and closed LLBL field lines is observations of counterstreaming low-energy electrons. The LLBL is often found to contain such streams of bi-directional electrons flowing in the magnetic field parallel and antiparallel directions with energies of typically $20-500 \mathrm{eV}$. These counterstreaming electrons are observed at low-altitudes (Zanetti et al., 1981), at mid-altitudes (Sharp et al., 1980; Collin et al., 1982; Lundin et al., 1987; Yoshioka et al., 2000), at highaltitudes (Lin et al., 1982; Hultqvist et al., 1991), and close to the magnetopause (Ogilvie et al., 1984; Farrugia et al., 1988; Klumpar et al., 1988; Traver et al., 1991; Fuselier et al., 1995, 1997; Sauvaud et al., 1997). Furthermore, counterstreaming electrons are present most of the time along the dayside magnetopause (Hall et al., 1991; Miyake et al., 1998). Counterstreaming electrons have also been used to define the LLBL. Takahashi et al. (1991) reported a change from electron and ion distributions peaked at $90^{\circ}$ pitch angle inside the magnetosphere to bidirectional field-aligned electron distributions in the morningside boundary layer. Several observations suggest that the electron streams change as the spacecraft crosses the LLBL. In the outer parts of the LLBL the density increases and the temperature decreases to values that are typical of the adjacent magnetosheath (Hall et al., 1991; Hapgood and Bryant, 1992; Lockwood and Hapgood, 1998; Bauer et al., 2001). 


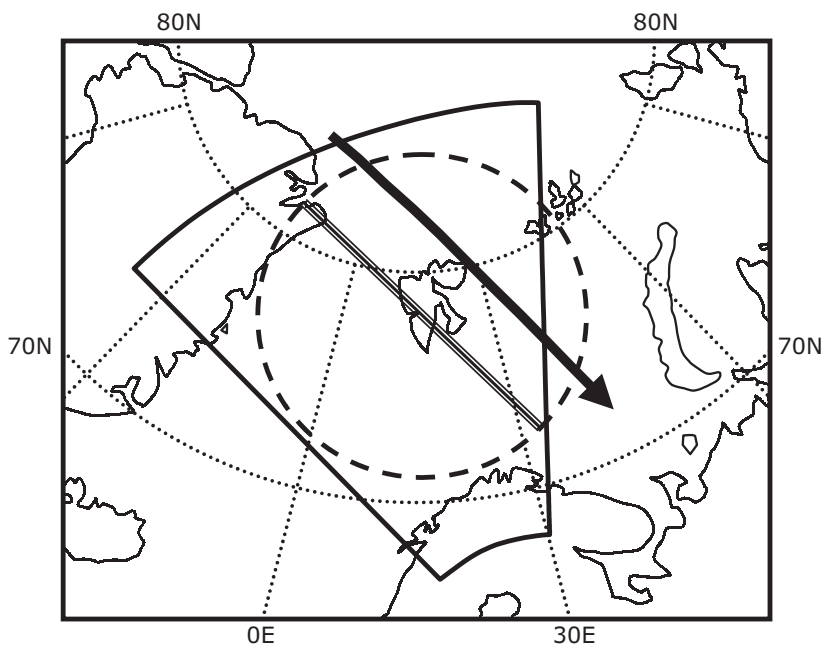

Fig. 1. Geographic coverage of the instrumentation used in this case study; the circular all-sky camera field-of-view, the fanshaped CUTLASS Finland HF radar field-of-view, and the meridian scanned by the MSP. The FAST trajectory is also indicated with an arrow.

Since the counterstreaming quite often is equal in both the parallel and anti-parallel magnetic field directions, several authors (e.g. Traver et al., 1991) have suggested counterstreaming as a signature of closed magnetic field lines. This requires the two independent ionospheric sources to produce identical fluxes and distribution functions of the accelerated electrons. Lockwood and Hapgood (1997) have presented an alternative approach for counterstreaming electrons on the most recently opened field lines through mixing of magnetospheric and magnetosheath electrons across the boundary. This is consistent with the observed similarities of plasma parameters in the outer LLBL and the adjacent magnetosheath (i.e. no discontinuity across the last closed field line). The Lockwood-Hapgood counterstreaming arises from the presence of both an injected magnetosheath population (which has travelled directly from the boundary to the spacecraft) and a population that was injected slightly earlier and has returned to the spacecraft from low altitudes. The dayside ionosphere is a region where field-aligned currents (FACs) are flowing (Iijima and Potemra, 1976a, 1976b). These early works used magnetic field perturbations from the Triad spacecraft to study the distribution of large-scale FACs in the high-latitude ionosphere and introduced the region 1, region 2, and cusp currents. Later, Erlandson et al. (1988) and Bythrow et al. (1988) suggested that the cusp current should be called the mantle current, as it is frequently observed on field lines that map to the plasma mantle poleward of the most intense magnetosheath-like electron precipitation. Very recent high-resolution measurements carried out by the Danish Ørsted satellite (e.g. Stauning et al., 2001) support this idea and suggest that the region 1 current is located equatorward of the cusp in the LLBL (Woch et al., 1993). The cusp FACs and the current carriers in the cusp region are, however, not well understood (Yamauchi et al., 1998). In the ionosphere FACs may close through horizontal currents, and their flow direction is determined by the IMF orientation (Friis-Christensen and Wilhjelm, 1975). These authors used ground magnetometers to study the DPY currents, and found them to flow east for $B_{Y}>0$ and west for $B_{Y}<0$, respectively.

A key feature of open/closed field lines (in addition to the properties of the particle population) is wave activity. On open cusp field lines electric field turbulence is commonly observed by satellites during both southward and northward IMF (e.g. Maynard et al., 1991; Basinska et al., 1992; Erlandson and Anderson, 1996; Tsurutani et al., 1998). In ground magnetograms Pc1 and Pc2 activity has also been identified (e.g. Menk et al., 1992; Dyrud et al., 1997). Combining PACE HF radar data and DMSP particle observations Baker et al. (1995) found that broad multi-component Doppler spectra are characteristic for the coherent HF radar backscatter in the cusp. This has also been confirmed in statistical studies (André et al., 2002), and recently, Moen et al. (2001) used HF backscatter to identify the cusp. The generating mechanisms for these decameter backscatter irregularities are, however, still open questions (Moen et al., 2002). HF radar backscatter in the cusp collocates with the $630 \mathrm{~nm}$ boundary at the equatorward edge, but extends poleward of the optical aurora and far into the polar cap.

In this paper we will combine observations from the multiinstrument FAST spacecraft and the CUTLASS Finland HF radar in the frame of ground-based optical images of the Type-1 cusp aurora to the south of Svalbard. According to the classification scheme of Sandholt et al. (1998), near magnetic noon such $630 \mathrm{~nm}$ dominated auroral forms are located south of Svalbard for periods of southward IMF (Type-1) and to the north of Svalbard for periods of northward IMF (Type-2). We will demonstrate that electric field turbulence is observed by FAST at mid-altitudes as CUTLASS also observed enhanced spectral width close to the footprint of the spacecraft. We report that the observed electric field turbulence is located near the equatorward edge of both the optical cusp and spectral width enhancements. Furthermore, we show that this wave activity occurs within a region of counterstreaming electrons on open magnetic field lines. Finally, we examine the current carriers (electrons and ions) within two narrow field-aligned current pairs in the cusp region.

\section{Instrumentation}

This paper utilizes ground-based optical data from the Svalbard stations Ny Ålesund and Longyearbyen, located near $75^{\circ}$ corrected geomagnetic latitude (CGMLAT) during a passage of the FAST spacecraft on 12 January 1997 (see Fig. 1). The FAST (Fast Auroral SnapshoT) spacecraft was launched into an $83^{\circ}$ inclination elliptical orbit of $350 \mathrm{~km}$ by $4175 \mathrm{~km}$ on 21 August 1996. Its orbital period is $133 \mathrm{~min}$, and the orbital motion evolves throughout the year so that the spacecraft crosses the auroral zones four times per orbit over a 
wide range of altitudes, local times and seasons. A more detailed description of the FAST mission is given by Carlson et al. (1998) and Pfaff et al. (2001), and the instruments we use in this paper are described by Carlson et al. (2001) (electron and ion electrostatic analyzers) and Ergun et al. (2001) and Elphic et al. (2001) (electric and magnetic field instruments). The Ny Ålesund meridian scanning photometer (MSP) was operating at two auroral emission lines, $557.7 \mathrm{~nm}$ and $630.0 \mathrm{~nm}$, scanning north-south approximately along the magnetic meridian. The Longyearbyen all-sky camera obtained images at the $630 \mathrm{~nm}$ line every $20 \mathrm{~s}$. Each image is cut at $70^{\circ}$ zenith angle, before it is projected to $250 \mathrm{~km}$ altitude and overlaid a geographic map.

The optical data is combined with data from the CUTLASS (Co-operative UK Twin Located Auroral Sounding System) Finland HF radar located at Hankasalmi (62.3 $\mathrm{N}$, $26.6^{\circ}$ E). CUTLASS Finland is one of the SuperDARN radars (Greenwald et al., 1995) and has been operational since February 1995. It has an array of 16 transmitting and receiving antennas. The radar can operate at frequencies between 8 and $20 \mathrm{MHz}$ in the HF band, and each antenna array is phased relative to the others to form an antenna pattern with maximum gain in one of the 16 azimuthal pointing directions (hereafter called beams). The beams are separated by $\sim 3.2^{\circ}$ and distributed around the radar boresite of $-12^{\circ}$ (i.e. west of geographic north). Consequently, Svalbard is centered within the field-of-view (see Fig. 1).

The coherent CUTLASS Finland radar measures backscatter echoes from field-aligned plasma irregularities in the high-latitude ionosphere (e.g. Greenwald et al., 1995). Transmitting a 7-pulse scheme and analyzing the auto-correlation function of the returning signals gives backscatter Doppler spectra. These spectra can be used to derive spectral characteristics like power, line-of-sight velocity and spectral width (e.g. Hanuise et al., 1993; Baker et al., 1995). In the F-region the backscattered echo is a trace of the $\boldsymbol{E} \times \boldsymbol{B}$ plasma drift (Villain et al., 1985; Ruohoniemi et al., 1987; Davies et al., 1999, 2000).

The radar field-of-view depends on the ionospheric conditions for radio wave propagation. To receive ionospheric backscatter over Svalbard the propagation mode most likely is the $1.5 \mathrm{~F}$ mode of $\mathrm{HF}$ radio wave propagation (Milan et al., 1997). This means that the transmitted radar signal is first refracted from the F-region ionosphere to the ground, before it is reflected into a second hop where some energy can be backscattered from irregularities in the F-region. In this way backscatter from far range is only possible if the conditions for ionospheric refraction are producing the first hop, followed by a forward scatter to the more distant irregularities. The refraction depends on the transmitted frequency and the distribution of ionospheric plasma density (both vertical and horizontal along the direction of the radar beam), as discussed by Milan et al. (1997), and studies have shown that the cusp region and dayside auroral oval behave like a hard target, even if the conditions for radio wave propagation change dramatically (Milan et al., 1998).

On 12 January 1997 the radar was operating at a frequency

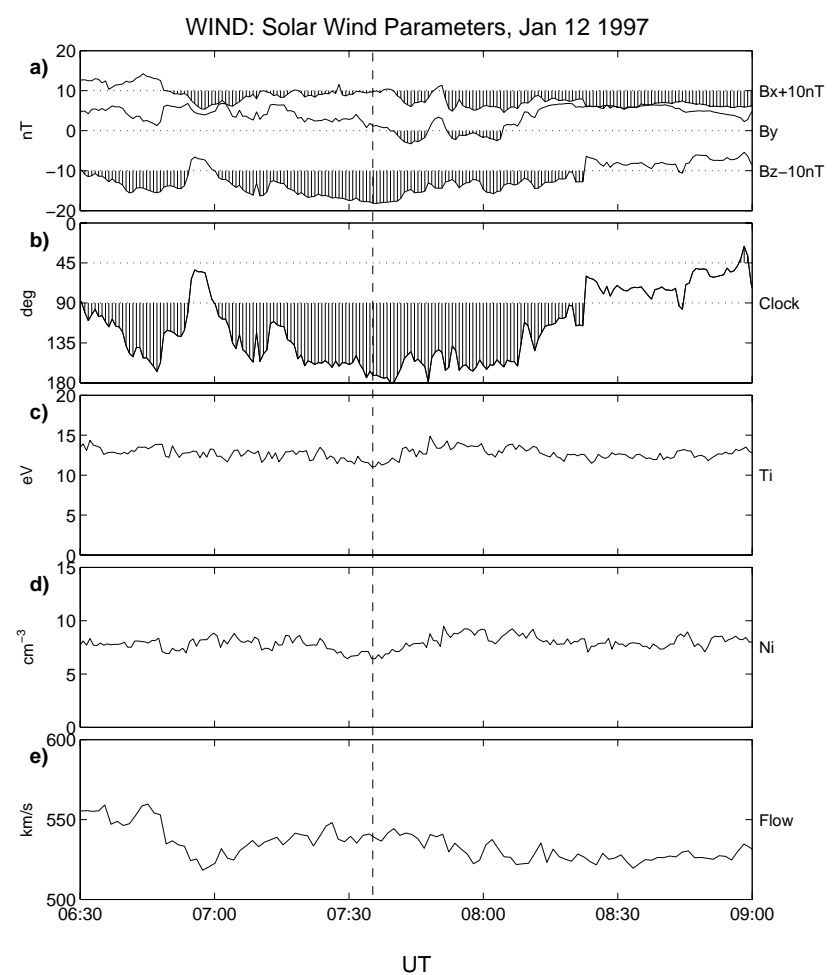

Fig. 2. Interplanetary magnetic field (IMF) and solar wind data from the Wind spacecraft for 12 January 1997: (a) the IMF $B_{X}, B_{Y}$ and $B_{Z}$ components, (b) the IMF clock angle, (c) the ion temperature, (d) the ion density, and (e) the solar wind flow velocity. The vertical line indicates the time of the event, assuming a 25 min time shift from Wind to the ionosphere.

of $10 \mathrm{MHz}$ and scanned through beams 15 to 0 (east to west) in descending order with a dwell time of $7 \mathrm{~s}$ at each beam, giving a fan-shaped field-of-view every $2 \mathrm{~min}$. For each beam a total of 75 range gates were sampled with a pulse length of $300 \mu \mathrm{s}$, corresponding to a range gate length of $45 \mathrm{~km}$. The time lag to the first gate was $1200 \mu \mathrm{s}$, and the coverage in range was from 180 to $3555 \mathrm{~km}$.

\section{Observations}

Solar wind parameters are obtained from three of the instruments on board the Wind spacecraft: the Magnetic Field Investigation (MFI) (Lepping et al., 1995), the Solar Wind Experiment (SWE) (Ogilvie et al., 1995), and the 3-D plasma (3-DP) analyzer (Lin et al., 1995). Figure 2 shows IMF and solar wind observations from 06:30 to 09:00 UT on 12 January 1997. Wind was located upstream of Earth, near (103, $-54,10) R_{E}$ in GSM coordinates, and the vertical guide line refers to the time of our event, when a $\sim 25$ min time delay from Wind to the ionosphere is used (Oksavik et al., 2000). Figure 2a gives the IMF $B_{X}, B_{Y}$, and $B_{Z}$ components in GSM coordinates, where shadings indicate negative values. The IMF was dominated by a rather stable and strongly 


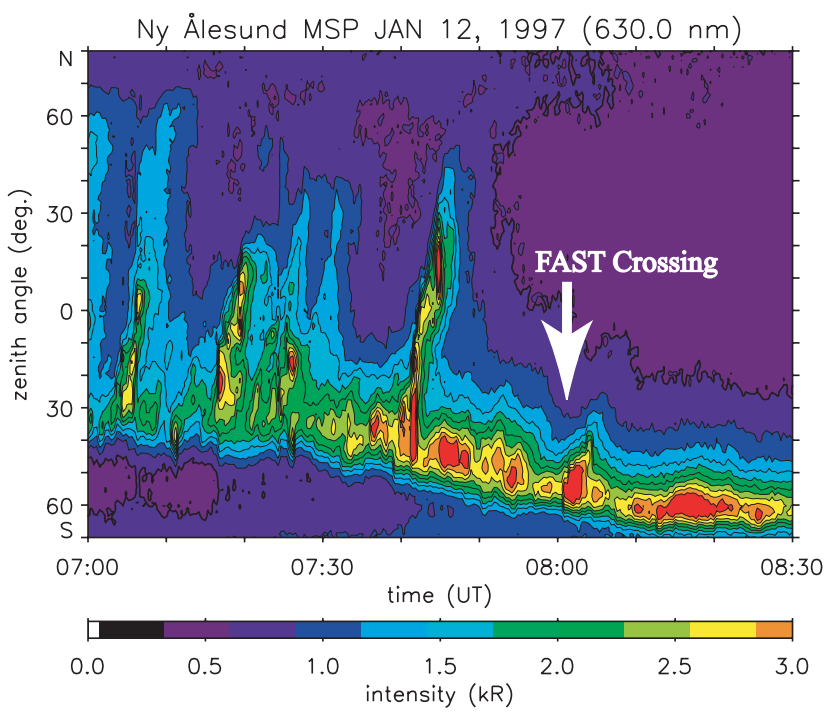

Fig. 3. Color-coded $630 \mathrm{~nm}$ meridian-scanning photometer intensities from Ny Ålesund. The white arrow indicates when the FAST spacecraft was crossing through the cusp aurora.

southward component $\left(B_{Z}=-8 \mathrm{nT}\right)$. Figure $2 \mathrm{~b}$ provides the IMF clock angle $\theta$ in the GSM Y-Z plane, see, e.g. Oksavik et al. (2000). Periods of southward IMF $\left(\theta>90^{\circ}\right)$ are indicated with shading, and $\theta$ is huge $\left(>150^{\circ}\right)$ for a long period, both before and after the event. Figures $2 \mathrm{c}-2 \mathrm{e}$ display the solar wind ion temperature, density, and bulk flow speed, respectively. These three parameters show only smaller variations, though their values are above average.

Figure 3 gives an overview of meridian-scanning photometer recordings from $\mathrm{Ny}$ Ålesund from 07:00 to 08:30 UT. An arrow is used to indicate the time when FAST passed over Svalbard around 08:02 UT. The $630 \mathrm{~nm}$ dominated Type-1 cusp aurora is located south of zenith, in good agreement with the very large clock angle (IMF strongly southward) in Fig. 2. Such auroral forms generally appears to the south of Svalbard during periods of southward IMF, while a different type (Type-2) is observed north of Svalbard whenever IMF is northward (Sandholt et al., 1998). Before 07:45 UT several poleward moving auroral forms occurred. However, this activity decreased as the aurora migrated equatorward in response to a long period of significant southward IMF. No poleward moving forms were detected near the FAST overflight.

Observations from the FAST spacecraft are shown in Fig. 4. The top three panels display electric and magnetic field data: (a) DC electric fields along the spacecraft velocity vector, (b) spin-axis component of the DC magnetometer oriented perpendicular to the orbital plane, where a positive (negative) slope indicates downgoing (upgoing) currents (Elphic et al., 1998), and (c) a $0.04-16 \mathrm{kHz}$ electric wave spectrogram. The last four panels of Fig. 4 show energy-time spectrograms in the 5-30000 eV energy range: (d) precipitating ions with pitch angles $-20^{\circ}$ to $20^{\circ}$, (e) outflowing ions with pitch angles $160^{\circ}$ to $200^{\circ}$, (f) precipitating electrons, and (g) outflowing electrons. The pitch angle intervals are chosen this narrow to make sure all detected particles are within the atmospheric loss cone. The loss cone at FAST altitudes is $\sim 30^{\circ}$ for this particular satellite pass, and the data shown in Fig. 4d-g should, therefore, be loss cone particles only. The grey shading in Fig. 4 refers to the interval between the two white arrows in Fig. 5, where the footprint of the equatorward moving FAST spacecraft is indicated on a $630 \mathrm{~nm}$ all-sky image from Longyearbyen superimposed onto a geographic latitude-longitude grid. The magnetic north-south and east-west azimuths of Longyearbyen are also indicated in Fig. 5 for reference. In this projection we have assumed the observed cusp aurora is concentrated around a typical altitude of $250 \mathrm{~km}$, and we have field line traced the FAST orbit to the same altitude.

A very sharp boundary is found in all panels of Fig. 4 around 08:02:45 UT, and this boundary will be discussed in more detail referring to Fig. 6 . Note for the moment that it closely matches the equatorward edge of the $630 \mathrm{~nm}$ cusp aurora in Fig. 5, and that equatorward of this boundary any magnetic deflections, electric field disturbances, and significant particle fluxes of energies $<10000 \mathrm{eV}$ are absent. Poleward of the boundary (before 08:02:45 UT) intense $<1 \mathrm{kHz}$ electric waves are observed (Fig. 4c), and this wave activity extends far into the polar cap and several degrees in latitude poleward of the visible aurora.

The mid-altitude ion spectrogram in Fig. 4d also reveals a familiar pattern often found in low-altitude spacecraft data. The low-energy ion cutoff or "staircase" cusp signatures with decreasing threshold energy vs. increasing latitude seen from 07:56:40 to 08:02:45 UT are known to be characteristic for the southward IMF cusp (e.g. Newell and Meng, 1991, 1995; Lockwood et al., 1998).

One of the greatest benefits of the FAST mission is the very high time resolution of the measurements that allows us to extract even more details about the fine-scale structures in the cusp aurora. Figure 6 presents two minutes of data (from 08:01 to 08:03 UT) in the same format as in Fig. 4. Two partly overlapping steps in the precipitating ion energies are identified in Fig. 6d. The first ion step (300-2000 eV) is from 08:01:40 to 08:02:30 UT, and the second one (2000$7000 \mathrm{eV}$ ) is from 08:02:17 to 08:02:40 UT. There is also a third short ion beam $(8000-15000 \mathrm{eV})$ from $08: 02: 40$ to 08:02:45 UT. For comparison the energies of the outflowing ions are typically less than $100 \mathrm{eV}$ (Fig. 6e).

During most of these ion steps the electrons are found to be counterstreaming (Fig. 6f-g). Throughout most of the satellite pass electron energies are typically less than $100 \mathrm{eV}$. However, as FAST traversed the bright equatorward edge of the cusp aurora 08:02:17 to 08:02:40 UT, significant electron fluxes reached energies up to almost $1000 \mathrm{eV}$, coinciding in time with the second ion step. It may also be noted that between 08:01:15 and 08:01:30 UT there are some $<100 \mathrm{eV}$ beams of downward electrons and upward ions surrounded by beams of upward moving electrons, suggesting narrow 

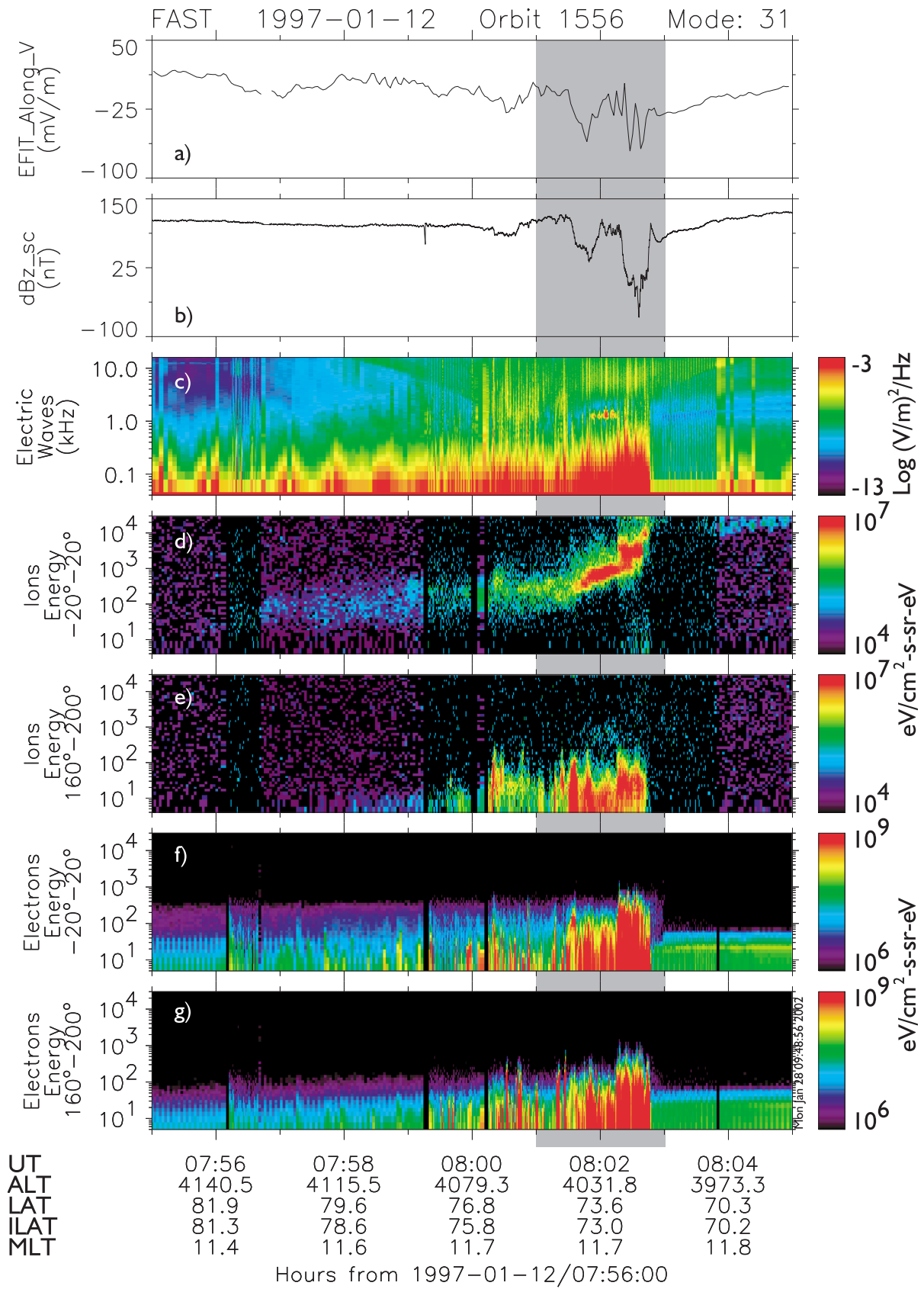

Fig. 4. FAST particle and field data from 07:55 to 08:05 UT. The seven panels show: (a) DC electric fields along the spacecraft velocity vector, (b) spin-axis component of the DC magnetometer oriented perpendicular to the orbital plane, (c) electric field wave spectrogram, (d) energy-time spectrogram for precipitating ions with pitch angles of $-20^{\circ}$ to $20^{\circ}$, (e) energy-time spectrogram for outflowing ions with pitch angles of $160^{\circ}$ to $200^{\circ}$, (f) energy-time spectrogram for precipitating electrons with pitch angles of $-20^{\circ}$ to $20^{\circ}$, and (g) energy-time spectrogram for outflowing electrons with pitch angles of $160^{\circ}$ to $200^{\circ}$. The grey shading indicates the time interval shown in Fig. 6 and the interval between the two white arrows in Fig. 5.

sheets of weak field-aligned potential drops of opposite polarities poleward of the cusp aurora.

Now, let us examine the rather complicated field-aligned current (FAC) system that FAST encountered crossing the cusp aurora. For this we use the slope of the observed spinaxis component of the DC magnetometer (that is oriented perpendicular to the orbital plane) shown in Fig. 6b, where a positive (negative) slope indicates downgoing (upgoing) currents (Elphic et al., 1998). In Fig. 6 this is shown with colored shading; blue shading indicates regions of upward or outflowing FAC, and red shading indicates regions where currents are flowing into the ionosphere. Two relatively clear pairs of FACs are found; the weaker one (08:01:32 to 08:02:01 UT) is close to the poleward edge, while the 


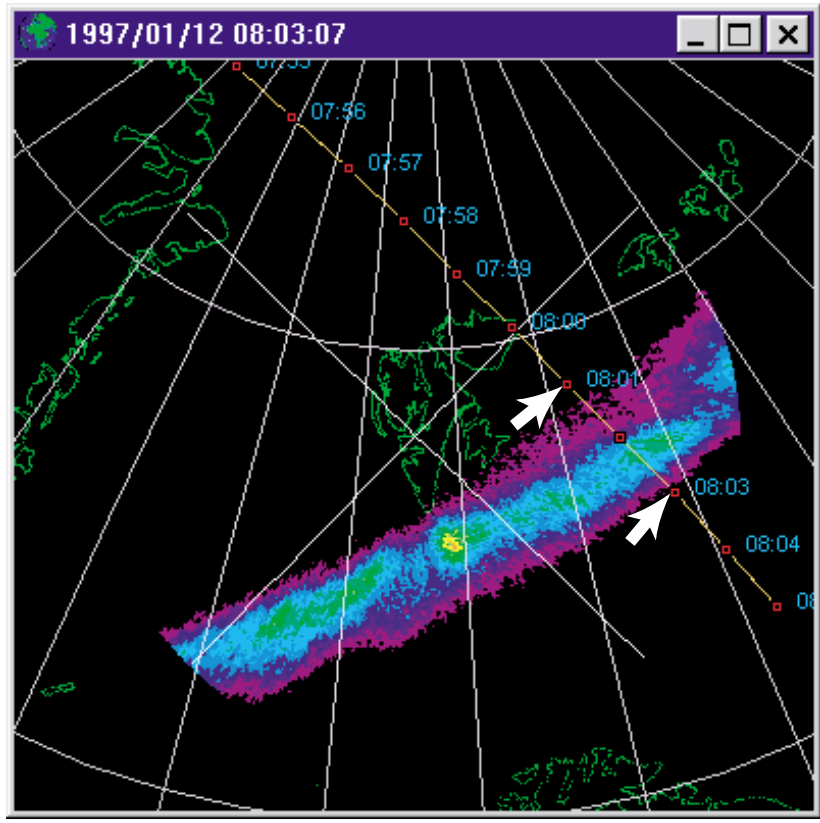

Fig. 5. All-sky image at $630 \mathrm{~nm}$ from Longyearbyen projected to $250 \mathrm{~km}$ altitude on a geographical grid, where the magnetic northsouth and east-west azimuths of Longyearbyen are shown for reference. The footprint of the FAST spacecraft is overlayed, and the two white arrows indicate the time interval of Fig. 6.

stronger one (08:02:19 to 08:02:47 UT) is at the brighter equatorward edge of the cusp aurora.

The first current system consists of an upward FAC from 08:01:32 to 08:01:37 UT and a downward FAC from 08:01:49 to 08:02:01 UT. The upward current is carried by a narrow beam (inverted $\mathrm{V}$ structure) of precipitating electrons with energies around $100 \mathrm{eV}$ and outflowing ions of energies less than $100 \mathrm{eV}$. On the other hand, the downward current is carried by a net outflow of electrons and a net inflow of ions. In this case the outflowing electrons have slightly higher energies than the precipitating ones, and the energy of the outflowing ions drops below $30-40 \mathrm{eV}$ while the precipitating ions have energies of 300-1000 eV.

The second current system is more complicated, with two internal fine-scale structures, though the main pattern is an upward FAC from 08:02:19 to 08:02:26 UT and a downward FAC from 08:02:43 to 08:02:47 UT. The upward FAC occurred in a region where two ion steps were overlapping, with precipitating ion energies from 1000 to $7000 \mathrm{eV}$. At the same time the outflowing ions had slightly elevated energies (still $<100 \mathrm{eV}$ ). The distribution of precipitating electrons had more electrons with energies $>100 \mathrm{eV}$ than the outflowing one, giving a net inflow of electron energy flux consistent with the upward current. The downward FAC was, however, only carried by the electrons. As is seen in Fig. 6d-e, ion fluxes are negligible after 08:02:43 UT. The distribution of outflowing electrons (Fig. 6g) had more electrons with energies $>100 \mathrm{eV}$ than the distribution of precipitating electrons
(Fig. 6f), resulting in a net outflow of electron energy flux giving the downward FAC. The two very thin structures between these upward and downward FACs are, unfortunately, so narrow that it is complicated to extract any details on the current carriers.

Throughout the cusp aurora crossing the DC electric field along the spacecraft velocity vector was negative (Fig. 6a). Since FAST was moving equatorward along the magnetic meridian, this corresponds to a westward component of the $\boldsymbol{E} \times \boldsymbol{B}$ drift in the ionosphere. Westward flow in the cusp ionosphere is favored during periods of IMF $B_{Y}>0$, as in Fig. 2. The westward flow was most intense close to the two field-aligned current systems.

Figure 7 presents a sequence of $630 \mathrm{~nm}$ all-sky images of the cusp aurora from Longyearbyen for the time interval 07:59:06 to $08: 15: 10$ UT (in the same format as in Fig. 5). Images are overlaid with yellow markers indicating range gates where spectral width enhancements of CUTLASS Finland were $>220 \mathrm{~m} / \mathrm{s}$. Furthermore, the FAST footprint is shown in the three first panels as the spacecraft was still within the field-of-view. The backscatter and spectral width enhancements of CUTLASS Finland started around 08:03 UT, as is shown in the third panel of Fig. 7, where only a few range gates give enhanced spectral width. The next image at 08:05:08 UT shows an increase in the number of range gates where the spectral width is $>220 \mathrm{~m} / \mathrm{s}$. These spectral width enhancements are rather continuous in time and space and located south-east of Svalbard until 08:15:10 UT (the very last image frame of Fig. 7), when the HF backscatter faded away. The region of increased spectral widths was located close to where FAST crossed the cusp aurora. Furthermore, when these spectral width enhancements were observed, they were also located close to the Type- 1 cusp aurora.

\section{Discussion}

Pfaff et al. (1998) presented initial observations of particles and fields obtained by the FAST spacecraft in the midaltitude cusp. They found that the equatorward particle boundary coincided with the equatorward edge of intense wave activity. Unfortunately, no ground-based data was available for that event. In the following subsections we will discuss the FAST and ground-based observations, focusing on three topics; the counterstreaming electrons, the electric field turbulence, and the field-aligned currents.

\subsection{Counterstreaming electrons in the LLBL/cusp}

Figure 6 shows that the electrons were counterstreaming as FAST crossed the cusp aurora. Counterstreaming electrons are quite often found in the LLBL (Hall et al., 1991; Miyake et al., 1998). Ogilvie et al. (1984) suggested that such electrons may originate from upward beams of accelerated ionospheric electrons seen at low altitude (Sharp et al., 1980; Collin et al., 1982; Klumpar and Heikkila, 1982; Burch et 


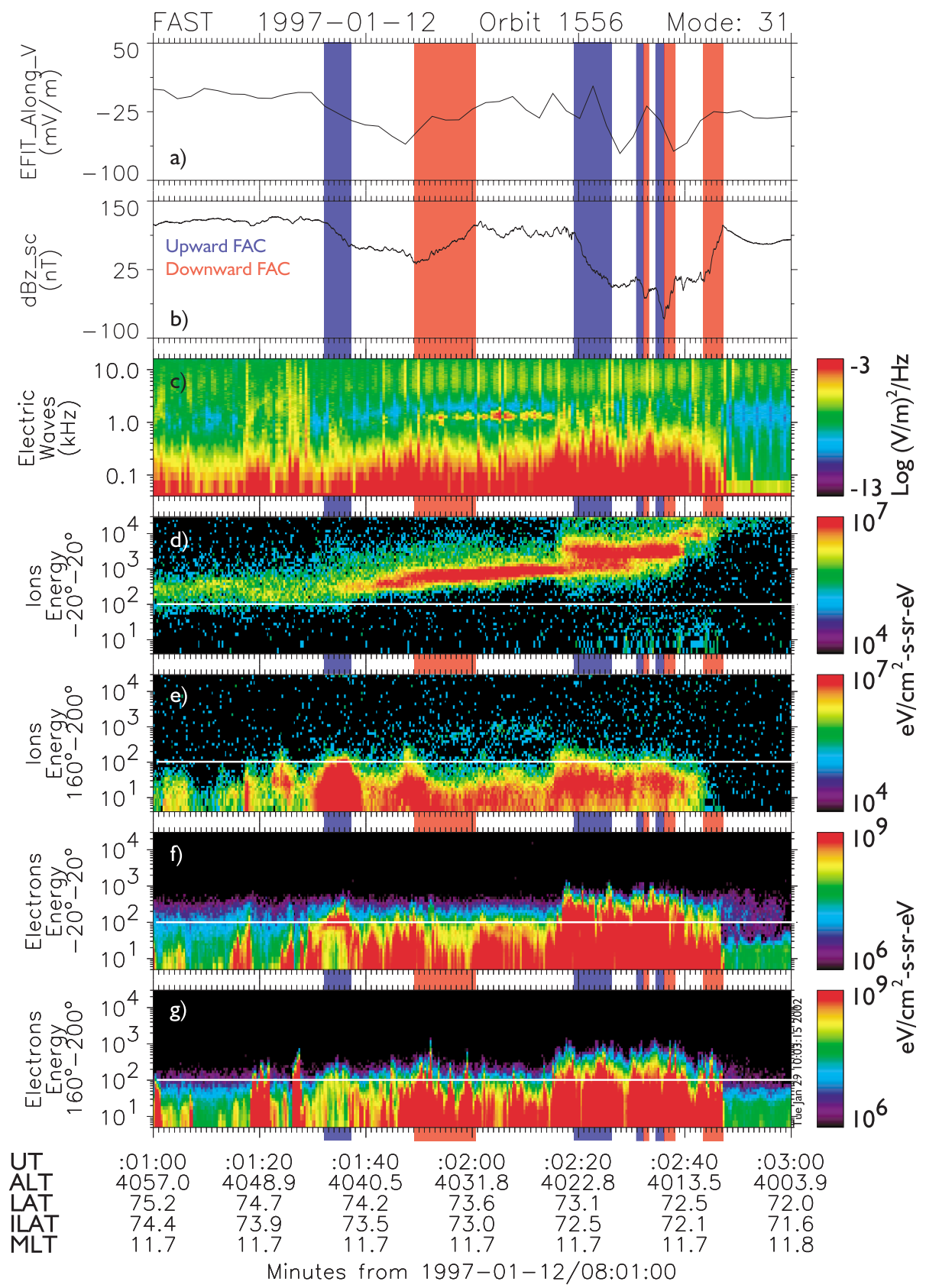

Fig. 6. An expanded view from 08:01 to 08:03 UT of the FAST particle and field data in Fig. 4. The blue and red shadings indicate regions of upward and downward field-aligned currents (FAC), respectively.

al., 1983). If ionospheric electrons in one hemisphere are accelerated and move freely in adiabatic motion along the magnetic field, they may reach the other hemisphere through the atmospheric loss cone. If the same process is taking place in both hemispheres, a counterstreaming electron distribution will be observed. This can even be taken one step further; if it is known that field-aligned electron beams are caused solely by acceleration of ionospheric electrons, the counterstreaming will be evidence for that particular magnetic field line being closed.
However, it is hard to see why the counterstreaming electrons presented in Fig. 6 should reside on closed field lines for several reasons. The counterstreaming electrons were observed simultaneously as precipitating stepped cusp signatures were seen in Fig. 6d. Stepped cusp signatures with low-energy ion cutoff are frequently observed by the lowaltitude DMSP spacecraft near noon, and they are generally regarded as temporal signatures of magnetopause reconnection on open magnetic field lines (Newell and Meng, 1991, 1995; Lockwood et al., 1998), though Trattner et al. (1999) have recently suggested that some stepped cusp sig- 


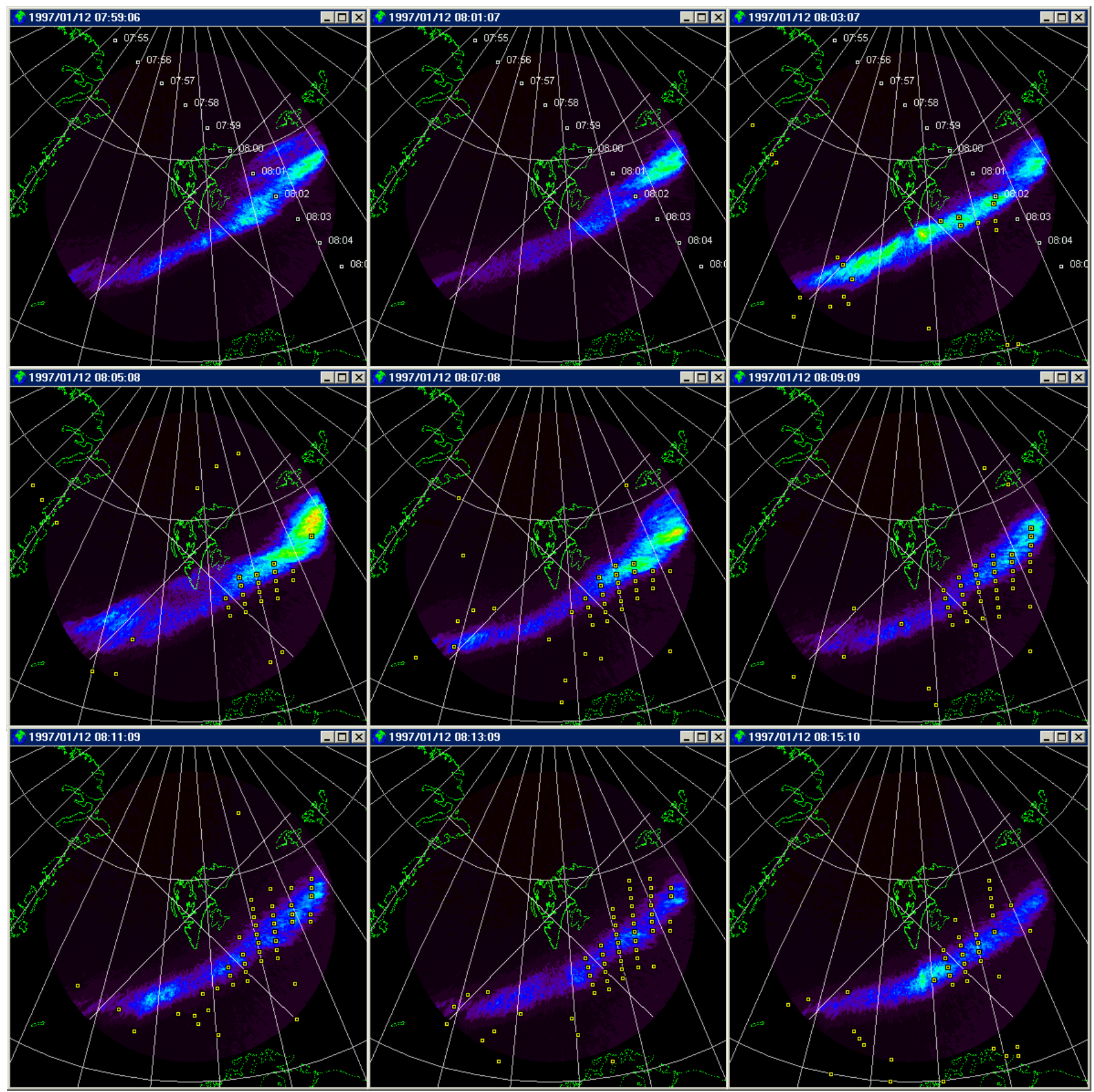

Fig. 7. Sequence of $630 \mathrm{~nm}$ all-sky images from Longyearbyen for the time interval 07:59:06 to 08:15:10 UT overlaid with yellow markers, indicating range gates where spectral widths of the CUTLASS Finland HF radar are $>220 \mathrm{~m} / \mathrm{s}$. In the first three panels the FAST footprint is also shown.

natures may be interpreted as spatial features. Nevertheless, the decrease in ion cutoff energy with increasing latitude for southward IMF can be successfully explained as $\boldsymbol{E} \times \boldsymbol{B}$ filtering of precipitating ions injected through magnetopause reconnection (Onsager et al., 1993). Cusp ion steps are predicted by the Cowley-Lockwood model of flow excitation (Cowley, 1998) and have been simulated in pulsating cusp models (Lockwood and Smith, 1994; Lockwood and Davis, 1995; Smith and Lockwood, 1996). Several authors have suggested that the LLBL, cusp and mantle are entirely on open field lines near noon when the IMF is southward as in our case (Onsager and Lockwood, 1997; Lockwood, 1998; Newell and Meng, 1998). Furthermore, the counterstreaming electrons were observed as FAST crossed the Type-1 (Sandholt et al., 1998) cusp aurora in Fig. 5. This cusp aurora was located far south of Svalbard, in response to the IMF being southward (Fig. 2). In the literature the cusp aurora is known to reconfigure within minutes in response to changes in the IMF (e.g. Moen et al., 1999; Sandholt et al., 1998). Placing the $630 \mathrm{~nm}$ cusp aurora in Fig. 5 entirely on closed field lines 
makes it difficult to explain why the dynamic cusp aurora always seems to be responding to the IMF. It is also unlikely that the two hemispheres produce identical fluxes, especially when it is winter in one hemisphere and summer in the other. On this basis, we suggest that the counterstreaming electrons were observed on open field lines. Savin et al. (1997) report ELF waves, together with counterstreaming electrons, which may suggest that electrons are accelerated at the magnetopause by such waves. Then the electrons would either be of magnetosheath or ionospheric origin. For the ionospheric origin an additional acceleration mechanism would be required at low altitude to pull the electrons out of the ionosphere.

Several observations suggest a change in electron streams as a spacecraft crosses the LLBL. In the outer parts of the LLBL the density increases and the temperature decreases to values that are typical of the adjacent magnetosheath (Hall et al., 1991; Hapgood and Bryant, 1992; Lockwood and Hapgood, 1998; Bauer et al., 2001). It is unlikely that these electrons could be of ionospheric origin, since it would require that ionospheric electrons are accelerated to match the electron population in the neighboring magnetosheath, leaving no room for a discontinuity across the last closed field line. Lockwood and Hapgood (1997) present a good explanation of the mixing of magnetospheric and magnetosheath electrons across this boundary. Furthermore, their analysis gives counterstreaming electrons on the most recently opened field lines. Therefore, such bi-directional streaming can arise from the presence of both an injected magnetosheath population (which has travelled directly from the boundary to the satellite) and a population that was injected slightly earlier and has returned to the satellite from low altitudes.

Counterstreaming electrons are seen in the LLBL, both during southward and northward interplanetary magnetic field (IMF), which may imply that most of the time reconnection is occurring somewhere on the magnetopause filling the boundary with newly reconnected field lines. Along these field lines counterstreaming magnetosheath electrons can be injected possibly with additional heating at the magnetopause. The electrons would then precipitate, mirror in low altitude, and return upwards. Lockwood and Hapgood $(1997,1998)$ have used ion observations and tangential stress balance tests to show that counterstreaming in the LLBL is well explained as being a response of the electron gas to ion flight time effects, which is required to maintain quasineutrality on newly-opened field lines (Burch, 1985). Traver et al. (1991) found a variation in the bi-directional stream across the LLBL and observed a "hot" tail in the distribution above $200 \mathrm{eV}$, which was enhanced over both magnetosheath and plasma sheet values at these energies. They concluded that an ionospheric source was more likely, since a magnetosheath origin would require some electron heating. However, recent observations of electron flows across the magnetopause (Onsager et al., 2001) show that such heating can occur. Hence, bi-directional electron streams in the LLBL can be viewed as evidence for open LLBL field lines.
Let us also look at the counterstreaming itself. The pitch angle distribution of the electrons was inspected (data not shown here), and it revealed that the electrons were highly field-aligned in both the magnetic field parallel and antiparallel directions with few electrons outside the two loss cones. In Sect. 3 we mentioned that the loss cone was estimated to $\sim 30^{\circ}$ at FAST altitudes, and Fig. $6 f$ shows electrons in the precipitating loss cone (pitch angles less than $20^{\circ}$ ). However, a $20^{\circ}$ pitch angle electron at FAST altitudes of $4000 \mathrm{~km}$ will only reach a pitch angle of $\sim 40^{\circ}$ in the ionosphere due to magnetic mirroring. The magnetic mirroring force is, therefore, not enough to return these electrons from below the spacecraft, and other physical processes must be involved in producing the upward flowing electrons in Fig. $6 \mathrm{~g}$. We can think of two possible mechanisms; upward acceleration due to DC and/or AC fields, or pitch angle scattering of the lowenergy electrons in collisions with the upper ionosphere.

Mechanisms for upward acceleration due to DC and/or AC fields has been suggested by several authors. Lundin et al. (1987) suggested that the electron conics could be caused by a time-varying accelerating potential that varies on time scales of one quarter bounce cycle, or alternatively, that the acceleration is not parallel to the magnetic field direction (scattering/heating is added and enables electrons to escape due to higher total energy). Hultqvist (1988) put forward a model to explain observations by Hultqvist et al. (1988) of upward field-aligned fluxes of energetic ions and electrons. In the Hultqvist (1988) model ions are accelerated in an upward electric DC field, while electrons are accelerated in a downward electric AC field (that appears to be quasi-static for the electrons and negligible for the ions). From the Oersted satellite Hosokawa et al. (2003) have presented high frequency $(0.2-5 \mathrm{~Hz})$ magnetic field fluctuations that were observed as the spacecraft crossed a region of high spectral width, and these magnetic field fluctuations were considered to be Alfvén waves. Such waves are commonly found in the cusp region (Chaston et al., 2003), and in a recent paper, $\mathrm{Su}$ et al. (2001) show that burst-like precipitating electrons are correlated with small-scale electric field fluctuations, some of which they identify as propagating Alfvén waves. Ongoing work even suggests that a pair of Alfvén waves moving in opposite directions may produce a counterstreaming distribution (Su et al., 2003).

However, in our case there is a limitation to the maximum strength of these DC and/or AC fields below the spacecraft. Auroral emissions in the $630 \mathrm{~nm}$ band (e.g. Fig. 5) are observed simultaneously in the ionosphere, and these emissions are generally believed to result from precipitating electrons colliding with atomic oxygen in $200-500 \mathrm{~km}$ altitude. Therefore, a significant portion of the precipitating electrons must be able to reach the upper ionosphere carrying sufficient energy flux to produce the observed $630 \mathrm{~nm}$ cusp aurora. On this basis we suggest an alternative mechanism that may also contribute to the counterstreaming and that may prove to be an important source for rayed red auroral arcs. The energy distribution of the precipitating electrons in the cusp contains a significant flux of electrons with energies less than $100 \mathrm{eV}$ 
(see Fig. 4). Compared with the more energetic electrons on the nightside (where the energies reach several tens of $\mathrm{keV}$ ) the electrons in the cusp may experience severe pitch angle scattering in collisions with the upper ionosphere (Banks et al., 1974). Due to their low energy the precipitating cusp electrons will not reach far into the ionosphere, and these electrons may be able to mirror without being lost through pitch angle scattering in collisions. Furthermore, these slow electrons may cause optical emissions both as they penetrate downwards and upwards in the ionosphere. This may be consistent with the wide altitude distribution often found for the rayed $630 \mathrm{~nm}$ cusp aurora. More model work will, however, be needed to examine how effective this mechanism will be.

\subsection{Spectral width enhancement and electric field turbu-} lence in the LLBL/cusp

Figure 7 shows that the spectral width enhancements starting at 08:03 UT were nearly collocated with the equatorward edge of the cusp aurora. It is clear that two conditions must be met for HF backscatter to occur; (1) right conditions for radio- wave propagation, and (2) field-aligned irregularities. According to Milan et al. (1997) the radio wave propagation mode for CUTLASS Finland HF backscatter from the cusp is the $1.5 \mathrm{~F}$ mode, since the signal cannot travel in a straight line due to Earth's curvature. Briefly explained this mode involves for the transmitted signal a refraction in the F2-region, followed by a ground reflection, before the signal finally reaches the ionospheric F-region field-aligned electron density irregularities over Svalbard. The backscatter then has to follow a similar route back to the CUTLASS Finland radar. The conditions for refraction (i.e. the ray path) depends on the operating frequency and the electron density profile (Milan et al., 1997; Danskin et al., 2002). Ionospheric tomography (e.g. Walker et al., 1998, Fig. 3) has revealed that the high-latitude ionosphere may be highly structured in latitude and altitude. Observations made by incoherent scatter radars in azimuth or elevation scanning modes have confirmed that these ionospheric structures extend both in latitude, longitude and altitude (e.g. Watermann et al., 1994; Valladares et al., 1999; Pryse et al., 2002), and at a given location the plasma density may change on time scales of a few minutes (Carlson et al., 2002).

Therefore, it is not unlikely that there was a change in the F-region over northern Scandinavia just before 08:03 UT allowing the $1.5 \mathrm{~F}$ HF radio wave propagation mode to start. Moen et al. (2001) have pointed out that the mid-winter solar zenith angle maximum near noon may play an important role in building up sufficient bottomside F-region plasma density for propagation path connectivity, and that co-rotation or other transport mechanisms place the plasma densities with reasonable repeatability in line with the propagation path from the CUTLASS Finland transmitter to the cusp reflection region over Svalbard. The fact that the spectral width enhancements in Fig. 7 mainly occurred in the eastern part of the field-of-view may in our case be related to the global convection pattern. Local magnetic noon at Longyearbyen is
08:45 UT, and since the IMF $B_{Y}$ component (Fig. 2a) was fairly small, it is expected that both the morning and evening convection cells would be driving the convection within the field-of-view. However, at high latitudes and at the given time only the evening convection cell would contain sunlit plasma in the F-region. Therefore, we suggest that these spectral width enhancements were observed in the eastern part of the field-of-view due to a buildup of F-region sunlit plasma density in the high latitude evening convection cell (i.e. over northern Scandinavia). The high latitude F-region plasma in the morning convection cell was not sunlit, and consequently, the CUTLASS signals were not able to reach the ionosphere west of Svalbard. This does not rule out the possibility that spectral width enhancements may still be present west of Svalbard. According to Moen et al. (2001) the buildup of F-region density for propagation connectivity appears like a switch for seeing the turn on of HF echoes, rather than the turn on of irregularities themselves. Statistical studies have shown that whenever backscatter is present the equatorward edge of spectral width enhancements show excellent agreement with low-altitude spacecraft observations of the statistical location of the cusp, and the HF radar cusp also migrates equatorward under IMF $B_{Z}$ south conditions (Yeoman et al., 2002).

It should, however, be noted that in Fig. 7 there appears to be a small gap between the cusp aurora and the spectral width enhancements. This is best seen around 08:07 and 08:09 UT, where the spectral width enhancements are located slightly equatorward of the cusp aurora. We have tried to change the altitude $(250 \mathrm{~km})$ used in the projection of the cusp aurora, but that did not help sufficiently. Therefore, the shift in latitude is rather related to the fact that we do not know the exact radio- wave propagation path. Range determination is based on time-of-flight of radar returns, and Fig. 7 indicates that ground range may be underestimated. According to Villain et al. (1985), it is important to know the meridional electron density profile when the irregularities are projected onto the geographical map. If the height assumption of the irregularity layer is wrong, the irregularities will be shifted in ground range, but the observed pattern will be preserved. For the present study no such meridional electron density data is available. It is, however, not unlikely that this assumption (especially during buildup or breakdown of HF backscatter) may lead to a change in altitude of the irregularities and consequently, a shift in ground range. In a recent paper, Yeoman et al. (2001) have evaluated the uncertainty in the location of backscatter by using the CUTLASS Iceland radar to observe artificially induced backscatter by the EISCAT Troms $\emptyset$ Heater. They found that the standard algorithm for backscatter ground range location is accurate to within $114 \pm 15 \mathrm{~km}$ for $1.5 \mathrm{~F}$ mode backscatter. In Fig. 7 the range gate resolution is $45 \mathrm{~km}$ (i.e. the uncertainty is $2-3$ range gates), and for that reason we interpret the spectral width enhancements to be collocated with the cusp aurora. This is also consistent with a study carried out by Rodger et al. (1995), where they reported that the equatorward edge of the ionospheric footprint of the optical cusp and the HF radar cusp are collocated 
to better than $1^{\circ}$ in latitude. This result has later been confirmed by other studies (Milan et al., 1999; Moen et al., 2001, 2002), and it is believed that the LLBL/cusp is a hard target for coherent HF radars (Milan et al., 1998).

The new aspect of this study is the passage of the multiinstrument FAST spacecraft providing detailed observations of fields and particles $4000 \mathrm{~km}$ over the spectral width enhancements. Yeoman et al. (1997) carried out a similar multiinstrument study using data from one of the low-altitude polar orbiting DMSP spacecraft to show a collocation of radar backscatter, cusp particle precipitation and optical signatures. Their data set did not give any information on the pitch angle distribution of the particles, nor did they have data on electric field turbulence. Figures 4 and 7 show that FAST observed electric field turbulence $2-3$ min before the CUTLASS Finland radar started to observe spectral width enhancements near the footprint of the field line. The broadband turbulence detected by FAST in the cusp is observed at frequencies $<1 \mathrm{kHz}$ in the spacecraft frame of reference. Since FAST was travelling at a speed of around $5 \mathrm{~km} / \mathrm{s}$, this corresponds to scale lengths $>5 \mathrm{~m}$ along the spacecraft trajectory. The typical scales within the broad-band spectrum would therefore correspond to the decameter scale of the irregularities giving HF backscatter seen by CUTLASS. Conjugated electric field observations from the DE-1 and DE-2 spacecraft by Weimer et al. (1985) have shown that smallscale electric field structures with scale lengths $<150 \mathrm{~km}$ do not map very efficiently along magnetic field lines to low altitudes in the auroral zone, and this damping is proportional to the ionospheric conductivity. However, in the cusp region the conductivity is typically much lower than in the nightside auroral zone (Aksnes et al., 2002), allowing for small-scale electric field structures to map along the magnetic field.

Therefore, our observations suggest a phenomenological relationship between HF cusp backscatter and wave activity on open field lines in the cusp region. The formation mechanisms of HF backscatter irregularities have not yet been agreed upon. The four mechanisms suggested in the literature are: gradient drift instability, shear instability, "stirring" or flux tube interchange, and current convective instability. The latter is a subset of the gradient drift instability (e.g. Tsunoda, 1988; Basu et al., 1994). For the active cusp geometry, with poleward flow up a gradient in the electron density, the gradient drift instability has been suggested as the dominant mode for driving the F-region plasma unstable.

Moen et al. (2002) studied the density gradient observed by ionospheric tomography in association with $630 \mathrm{~nm}$ cusp aurora and a well-defined edge of HF radar cusp backscatter. They found a linear growth rate for gradient drift instability of $12 \mathrm{~min}$ (Tsunoda, 1988). The tomographic technique requires observations to be made for a range of ray-path geometries over a period of several minutes. As pointed out by Moen et al. (2002) the resultant integration effect in a poleward convecting flow will act to smooth out the density gradient to some degree, so that the growth time calculated could be an overestimate by possibly up to an order of magnitude. However, they concluded on the basis of the average large- scale gradient imaged by tomography that a time scale of the order of minutes would be needed for the irregularities to develop, during which time the prevailing convection would have carried the ionization poleward by a distance greater than the spatial resolution of the measurements $(\sim 25 \mathrm{~km})$. Hence, a clear spatial separation would be expected between the backscatter boundary and the boundary of the cusp auroral emissions. However, no such division was observed and that led Moen et al. (2002) to conclude that the operation of the gradient-drift mechanism on the observed meso-scale gradient was inadequate to explain the observations.

The collocation in latitude of the onsets of the smallscale irregularities responsible for backscatter and the optical emissions is most easily explained if both have a common source. Red-line cusp aurora arises from precipitation of low-energy magnetosheath particles that also cause enhancements in electron density at F-region altitudes. Backscattering of the radar signals arises from irregularities transverse to the magnetic field at the Bragg scale, which is about $15 \mathrm{~m}$ for the current observations. In this paper we have revealed prominent evidence for a near collocation of the equatorward edge of electric field irregularities imposed on the ionosphere and formation of cusp backscatter irregularities. The strong electric field turbulence will give rise to flow shear instability, and hence, plasma irregularities, as proposed by Baker et al. (1995).

Simulations by André et al. (1999, 2000a, b) suggest that the widening of HF Doppler spectra can be explained by the presence of a broad-band wave in the Pc1-Pc2 frequency band, though more precise calculations by Ponomarenko and Waters (2003) have shown that the results of André et al. were slightly overestimated. A recent study of Hosokawa et al. (2003) documented that high-frequency $(0.2-5 \mathrm{~Hz}) \mathrm{mag}$ netic field fluctuations occur simultaneously with wide HF radar spectra. In this paper we have documented the electric field fluctuations.

\subsection{Field-aligned currents in the LLBL/cusp}

The large-scale characteristics of FACs in the cusp region, their relationship to the IMF, polar convection, ionospheric currents and ULF-VLF waves were reviewed by Potemra and Zanetti (1985). However, FACs in the cusp region are not well understood and the current carriers are not well known (Yamauchi et al., 1998). For this reason we presented Fig. 6 showing that FACs in the cusp region were highly structured, with two thin current sheet pairs. The first FAC pair was located near the poleward edge, and the other pair at the equatorward edge of the Type- 1 cusp aurora. In both FAC pairs there was a downward FAC on the equatorward side and a upward FAC on the poleward side.

The poleward FAC pair was observed in a region of mantle precipitation, and the equatorward FAC pair occurred in a region of cusp ion steps. Lockwood et al. (2001) have predicted FACs around cusp ion steps produced by pulsed reconnection for periods with large IMF $B_{Y}$. In the Northern Hemisphere ionosphere such patches of newly-open flux 
move westward for $B_{Y}>0$ and eastward for $B_{Y}<0$. Figure 6 shows that the stepped cusp signatures (panel d) were related to FACs. The downward FAC around 08:02:45 UT was located just equatorward of the highest energy ion step, and an upward FAC was observed around 08:02:20 UT in an area of two partly overlapping ion steps. Furthermore, two very narrow up/down FAC pairs were observed in the time interval in between 08:02:30 to 08:02:40 UT. One of these FAC pairs was located close to the equatorward edge of the partly overlapping ion steps, and the other FAC pair was found at the transition between the two highest energy steps. The FAC flow directions of the present study are also consistent with Lockwood et al. (2001), even if the IMF is $B_{Z}$ south dominated with a only a small positive $B_{Y}$. It should also be mentioned that the downward FAC around 08:02:45 UT is located slightly equatorward of the ion steps and the cusp aurora, and this current is carried by outflowing electrons. Klumpar and Heikkila (1982) have reported similar observations of outflowing electrons carrying a downward FAC and suggested such electrons could be accelerated out of the ionosphere by a downward electric field.

It should be noted that the electron precipitation and outflow are highly structured in the cusp region. The FAST observations indicate narrow structures in the electron precipitation/outflow on spatial scales less than a few kilometers. In the mantle the FACs are mainly carried by the electrons, in the cusp/LLBL the ion steps may also contribute with a significant fraction of the total current. Modulations and small-scale size differences in the precipitating and outflowing electron fluxes may be an important source for FACs in the cusp region. The all-sky image in Fig. 5 showed only one continuous east-west elongated arc, and the electron and ion precipitation did not separate into two parts either. Allsky imagers (including ground-based magnetometers) may, however, not provide the spatial resolution needed to monitor such narrow current filaments of only a few tens of kilometers in width. High-resolution narrow-angle auroral images and simultaneous incoherent scatter radar observations have provided in evidence that small-scale structures of less than $100 \mathrm{~m}$ in width do exist in the cusp region (SedgemoreSchulthess et al., 1999). These authors found enhanced radar spectra related to $630 \mathrm{~nm}$ auroral emissions, which they suggested were signatures of thin FAC bursts from energetic auroral precipitation. On this basis it may seem artificial to try to assign FACs to distinct regions (like R1, R2, and mantle), as several small-scale FACs are observed to flow in opposite directions within the cusp region. This may also support the Lockwood et al. (2001) pulsed reconnection mechanism giving FAC between cusp ion steps.

\section{Conclusion}

We have studied observations from the multi-instrument FAST spacecraft during a meridional crossing of the cusp region within the field-of-view of the CUTLASS Finland HF radar and an all-sky imager. Conclusions of this case study are:

1. Counterstreaming electrons were observed on open field lines in the LLBL/cusp and were associated with Type1 cusp aurora. On this basis we suggest that such counterstreaming low-energy electrons may be an important source for rayed (i.e. extending in altitude) red arcs in the cusp region through pitch angle scattering in collisions with the upper atmosphere.

2. The counterstreaming electrons were observed simultaneously with stepped cusp signatures, and the cusp ion steps were associated with thin sheets of fine-scale field-aligned currents flowing near the edges of the ion steps.

3. Cusp backscatter targets were observed in association with electric field turbulence. This suggests that flow shear instability plays an important role for the formation of backscatter irregularities. Within one backscatter range gate (45 km long) there are strong flow shears $(>5 \mathrm{~m})$ causing a wide velocity distribution, which is consistent with a wide Doppler spectrum.

Acknowledgements. We acknowledge the use of data from the Coordinated Data Analysis Web; Wind Solar Wind Experiment (PI: K. Ogilvie), Wind Magnetic Field Experiment (PI: R. Lepping), and Wind 3-D Plasma Analyzer (PI: R. Lin). CUTLASS is supported by the UK Particle Physics and Astronomy Research Council (PPARC), the Swedish Institute for Space Physics, and the Finnish Meteorological Institute in Helsinki. Financial support has been provided by the Norwegian Research Council and AFOSR Task 2311AS.

Topical Editor T. Pulkkinen thanks J.-C. Cerisiere and H. C. Carlson for their help in evaluating this paper.

\section{References}

Aksnes, A., Stadsnes, J., Bjordal, J., Østgaard, N., Vondrak, R. R., Detrick, D. L., Rosenberg, T. J., Germany, G. A., and Chenette, D.: Instantaneous ionospheric global conductance maps during an isolated substorm, Ann. Geophysicae, 20, 1181, 2002.

André, R., Pinnock, M., and Rodger, A. S.: On the SuperDARN autocorrelation function observed in the ionospheric cusp, Geophys. Res. Lett., 26, 3353, 1999.

André, R., Pinnock, M., and Rodger, A. S.: Identification of the low-altitude cusp by Super Dual Auroral Radar Network radars: A physical explanation for the empirically derived signature, J. Geophys. Res., 105, 27 081, 2000a.

André, R., Pinnock, M., Villain, J.-P., and Hanuise, C.: On the factor conditioning the Doppler spectral width determined from $\mathrm{Su}-$ perDARN HF radars, Int. J. Geomagn. Aeron., 2, 77, 2000 b.

André, R., Pinnock, M., Villain, J.-P., and Hanuise, C.: Influence of magnetospheric processes on winter HF radar spectra characteristics, Ann. Geophysicae, 20, 1783, 2002.

Baker, K. B., Dudeney, J. R., Greenwald, R. A., Pinnock, M., Newell, P. T., Rodger, A. S., Mattin, N., and Meng, C.-I.: HF radar signatures of the cusp and low-latitude boundary layer, J. Geophys. Res., 100, 7671, 1995.

Banks, P. M., Chappell, C. R., and Nagy, A. F.: A new model for the interaction of auroral electrons with the atmosphere: Spectral degraduation, backscatter, optical emission, and ionization, J. Geophys. Res., 79, 1459, 1974. 
Basinska, E. M., Burke, W. J., Maynard, N. C., Hughes, W. J., Winningham, J. D., and Hanson, W. B.: Small-Scale Electrodynamics of the cusp with northward interplanetary magnetic field, J. Geophys. Res., 97, 6369, 1992.

Basu, Sa., Basu, Su., Chaturvedi, P. K., and Bryant, Jr., C. M.: Irregularity structures in the cusp/cleft and polar cap regions, Radio Sci., 29, 195, 1994.

Bauer, T. M., Treumann, R. A., and Baumjohann, W.: Investigation of the outer and inner low-latitude boundary layers, Ann. Geophysicae, 19, 1065, 2001.

Burch, J. L.: Quasi-neutrality in the polar cusp, Geophys. Res. Lett., 12, 469, 1985.

Burch, J. L., Reiff, P. H., and Sugiura, M.: Upward electron beams measured by DE-1: A primary source of dayside region-1 Birkeland currents, Geophys. Res. Lett., 10, 753, 1983.

Bythrow, P. F., Potemra, T. A., Erlandson, R. E., Zanetti, L. J., and Klumpar, D. M.: Birkeland currents and charged particles in the high-latitude prenoon region: A new interpretation, J. Geophys. Res., 93, 9791, 1988.

Carlson, C. W., Pfaff, R. F., and Watzin, J. G.: The Fast Auroral SnapshoT (FAST) mission, Geophys. Res. Lett., 25, 2013, 1998.

Carlson, C. W., McFadden, J. P., Turin, P., Curtis, D. W., and Magoncelli, A.: The electron and ion plasma experiment for FAST, Space Sci. Rev., 98, 33, 2001.

Carlson, H. C., Oksavik, K., Moen, J., van Eyken, A. P., and Guio, P.: ESR mapping of polar-cap patches in the dark cusp, Geophys. Res. Lett., 29 (10), 1386, doi:10.1029/2001GL014087, 2002.

Chaston, C. C., Bonnell, J. W., Carlson, C. W., McFadden, J. P., Ergun, R. E., and Strangeway, R. J.: Properties of small-scale Alfvén waves and accelerated electrons from FAST, J. Geophys. Res., 108 (A4), 8003, doi:10.1029/2002JA009420, 2003.

Collin, H. L., Sharp, R. D., and Shelley, E. G.: The occurrence and characteristics of electron beams over the polar regions, J. Geophys. Res., 87, 7504, 1982.

Cowley, S. W. H.: Excitation of flow in the Earth's magnetosphereionosphere system: Observations by incoherent-scatter radar, in: Polar Cap Boundary Phenomena, edited by J. Moen et al., p. 127, Kluwer Acad., Norwell, Mass., 1998.

Danskin, D. W., Koustov, A. V., Ogawa, T., Nishitani, N., Nozawa, S., Milan, S. E., Lester, M., and Andre, D.: On the factors controlling occurrence of F-region coherent echoes, Ann. Geophysicae, 20, 1385, 2002

Davies, J. A., Lester, M., Milan, S. E., and Yeoman, T. K.: A comparison of velocity measurements from the CUTLASS Finland radar and the EISCAT UHF system, Ann. Geophysicae, 17, 892, 1999.

Davies, J. A., T. K. Yeoman, T. K., Lester, M., and Milan, S. E.: A comparison of F-region ion velocity observations from the EISCAT Svalbard and VHF radars with irregularity drift velocity measurements from the CUTLASS Finland HF radar, Ann. Geophysicae, 18, 589, 2000.

Dyrud, L. P., Engebretson, M. J., Posch, J. L., Hughes, W. J., Fukunishi, H., Arnoldy, R. L., Newell, P. T., and Horne, R. B.: Ground observations and possible source regions of two types of Pc 12 micropulsations at very high latitudes, J. Geophys. Res., 102, 27011,1997

Elphic, R. C., Bonnell, J. W., Strangeway, R. J., Kepko, L., Ergun, R. E., McFadden, J. P., Carlson, C. W., Peria, W., Cattell, C. A., Klumpar, D., Shelley, E., Peterson, W., Möbius, E., Kistler, L., and Pfaff, R.: The auroral current circuit and field-aligned currents observed by FAST, Geophys. Res. Lett., 25, 2033, 1998.

Elphic, R. C., Means, J. D., Snare, R. C., Strangeway, R. J., Kepko,
L., and Ergun, R. E.: Magnetic field instruments for the Fast Auroral Snapshot Explorer, Space Sci. Rev., 98, 151, 2001.

Ergun, R. E., Carlson, C. W., Mozer, F. S., Delory, G. T., Temerin, M., McFadden, J. P., Pankow, D., Abiad, R., Harvey, P., Wilkes, R., Primbsch, H., Elphic, R., Strangeway, R., Pfaff, R., and Cattell, C. A.: The FAST satellite fields instrument, Space Sci. Rev., 98, 67, 2001

Erlandson, R. E. and Anderson, B. J.: Pc 1 waves in the ionosphere: A statistical study, J. Geophys. Res., 101, 7843, 1996.

Erlandson, R. E., Zanetti, L. J., Potemra, T. A., Bythrow, P. F., and Lundin, R.: IMF $B_{y}$ dependence of region 1 Birkeland currents near noon, J. Geophys. Res., 93, 9804, 1988.

Farrugia, C. J., Rijnbeek, R. P., Saunders, M. A., Southwood, D. J., Rodgers, D. J., Smith, M. F., Chaloner, C. P., Hall, D. S., Christiansen, P. J., and Woolliscroft, L. J. C.: A multi-instrument study of flux transfer event structure, J. Geophys. Res., 93, 14465 , 1988

Friis-Christensen, E. and Wilhjelm, J.: Polar cap currents for different directions of the interplanetary magnetic field in the Y-Z plane, J. Geophys. Res., 80, 1248, 1975.

Fuselier, S. A., Anderson, B. J., and Onsager, T. G.: Particle signatures of magnetic topology at the magnetopause: AMPTE/CCE observations, J. Geophys. Res., 100, 11 805, 1995.

Fuselier, S. A., Anderson, B. J., and Onsager, T. G.: Electron and ion signatures of field line topology at the low-shear magnetopause, J. Geophys. Res., 102, 4847, 1997.

Greenwald, R. A., Baker, K. B., Dudeney, J. R., Pinnock, M., Jones, T. B., Thomas, E. C., Villain, J.-P., Cerisier, J.-C., Senior, C., Hanuise, C., Hunsucker, R. D., Sofko, G., Koehler, J., Nielsen, E., Pellinen, R., Walker, A. D. M., Sato, N., and Yamagishi, H.: DARN/SuperDARN a global view of the dynamics of highlatitude convection, Space Sci. Rev., 71, 761, 1995.

Hall, D. S., Chaloner, C. P., Bryant, D. A., Lepine, D. R., and Tritakis, V. P.: Electrons in the boundary layers near the dayside magnetopause, J. Geophys. Res., 96, 7869, 1991.

Hanuise, C., Villain, J. P., Gresillon, D., Cabrit, B., Greenwald, R. A., and Baker, K. B.: Interpretation of HF radar ionospheric Doppler spectra by collective wave scattering theory, Ann. Geophysicae, 11, 29, 1993.

Hapgood, M. A. and Bryant, D. A.: Exploring the magnetospheric boundary layer, Planet. Space Sci., 40, 1431, 1992.

Hosokawa, K., Yamashita, S., Stauning, P., Sato, N., Yukimatu, A. S., and Iyemori, T.: Origin of the SuperDARN broad Doppler spectra: simultaneous observation with Oersted satellite magnetometer, Ann. Geophysicae, Accepted for publication, 2003.

Hultqvist, B.: On the acceleration of electrons and positive ions in the same direction along magnetic field lines by parallel electric fields, J. Geophys. Res., 93, 9777, 1988.

Hultqvist, B., Lundin, R., Stasiewicz, K., Block, L., Lindqvist, P.A., Gustafsson G., Koskinen, H., Bahnsen, A., Potemra, T. A., and Zanetti, L. J.: Simultaneous observation of upward moving field-aligned energetic electrons and ions on auroral zone field lines, J. Geophys. Res., 93, 9765, 1988.

Hultqvist, B., Vo, H., Lundin, R., Aparicio, B., Lindqvist, P.-A., Gustafsson, G., and Holback, B.: On the upward acceleration of electrons and ions by low-frequency electric field fluctuations observed by Viking, J. Geophys. Res., 96, 11 609, 1991.

Iijima, T., and Potemra, T. A.: The amplitude distribution of fieldaligned currents at northern high latitudes observed by Triad, J. Geophys. Res., 81, 2165, 1976a.

Iijima, T. and Potemra, T. A.: Field-aligned currents in the dayside cusp observed by Triad, J. Geophys. Res., 81, 5971, 1976b. 
Klumpar, D. M. and Heikkila, W. J.: Electrons in the ionospheric source cone: evidence for runaway electrons as carriers of downward Birkeland currents, Geophys. Res. Lett., 9, 873, 1982.

Klumpar, D. M., Quinn, J. M., and Shelley, E. G.: Counterstreaming electrons at the geomagnetic equator near $9 R_{E}$, Geophys. Res. Lett., 15, 1295, 1988.

Lepping, R. P., Acuña, M. H., Burlaga, L. F., Farrell, W. M., Slavin, J. A., Schatten, K. H., Mariani, F., Ness, N. F., Neubauer, F. M., Whang, Y. C., Byrnes,J.B., Kennon, R. S., Panetta, P. V., Scheifele, J., and Worley, E. M.: The Wind magnetic field investigation, Space Sci. Rev., 71, 207, 1995.

Lin, C. S., Burch, J. L., Winningham, J. D., Menietti, J. D., and Hoffman, R. A. : DE-1 observations of counterstreaming electrons at high altitudes, Geophys. Res. Lett., 9, 925, 1982.

Lin, R. P., Anderson, K. A., Ashford, S., Carlson, C., Curtis, D., Ergun, R., Larson, D., McFadden, J., McCarthy, M., Parks, G. K., Rme, H., Bosqued, J.M., Coutelier, J., Cotin, F., d'Uston, C., Wenzel, K.-P., Sanderson, T. R., Henrion, J., Ronnet, J. C., and Paschmann, G.: A three-dimensional plasma and energetic particle investigation for the Wind spacecraft, Space Sci. Rev., 71, 125, 1995.

Lockwood, M.: Identifying the open-closed field line boundary, in: Polar Cap Boundary Phenomena, edited by J. Moen et al., p. 73, Kluwer Acad., Norwell, Mass., 1998.

Lockwood, M. and Davis, C. J.: Occurrence probability, width and number of steps of cusp precipitation for fully pulsed reconnection at the dayside magnetopause, J. Geophys. Res., 100, 7626, 1995.

Lockwood, M. and Hapgood, M. A.: How the magnetopause transition parameter works, Geophys. Res. Lett., 24, 373, 1997.

Lockwood, M. and Hapgood, M. A.: On the cause of a magnetospheric flux transfer event, J. Geophys. Res., 103, 26 453, 1998.

Lockwood, M. and Smith, M. F.: Low and middle altitude cusp particle signatures for general magnetospause reconnection rate variations: 1. Theory, J. Geophys. Res., 99, 8531, 1994.

Lockwood, M., Fuselier, S., Walker, A. D. M., and Søraas, F.: A summary of the NATO ASI on polar cap boundary phenomena, in: Polar Cap Boundary Phenomena, edited by J. Moen et al., p. 415, Kluwer Acad., Norwell, Mass., 1998.

Lockwood, M., Milan, S. E., Onsager, T., Perry, C. H., Scudder, J. A., Russell, C. T., and Brittnacher, M.: Cusp ion steps, fieldaligned currents and poleward moving auroral forms, J. Geophys. Res., 106, 29 555, 2001.

Lundin, R., Eliasson, L., Hultqvist, B., and Stasiewicz, K.: Plasma energetization on auroral field lines as observed by the Viking spacecraft, Geophys. Res. Lett, 14, 443, 1987.

Maynard, N. C., Aggson, T. L., Basinska, E. M., Burke, W. J., Craven, P., Peterson, W. K., Sugiura, M., and Weimer, D. R.: Magnetospheric boundary dynamics: DE 1 and DE 2 observations near the magnetopause and cusp, J. Geophys. Res., 96, 3505, 1991.

Menk, F. W., Fraser, B. J., Hansen, H. J., Newell, P. T., Meng, C.I., and Morris, R. J.: Identification of the magnetospheric cusp and cleft using Pc1-2 ULF pulsations, J. Atmos. Terr. Phys., 54, 1021, 1992.

Milan, S. E., Yeoman, T. K., Lester, M., Thomas, E. C. and Jones, T. B.: Initial backscatter occurrence statistics from the CUTLASS HF radars, Ann. Geophysicae, 15, 703, 1997.

Milan, S. E., Yeoman, T. K., and Lester, M.: The dayside auroral zone as a hard target for coherent HF radars, Geophys. Res. Lett., 25, 3717, 1998

Milan, S. E., Lester, M., Cowley, S. W. H., Moen, J., Sandholt, P.
E., and Owen, C. J.: Meridian-scanning photometer, coherent HF radar, and magnetometer observations of the cusp: a case study, Ann. Geophysicae, 17, 159, 1999.

Miyake, W., Mukai, T. and Kaya, N.: A statistical study of fieldaligned electron beams associated with ion conics events, Ann. Geophysicae, 16, 940, 1998.

Moen, J., Carlson, H. C., and Sandholt, P. E.: Continuous observations of cusp auroral dynamics in response to an IMF $B_{Y}$ polarity change, Geophys. Res. Lett, 26, 1243, 1999.

Moen, J., Carlson, H. C., Milan, S. E., Shumilov, N., Lybekk, B., Sandholt, P. E. and Lester, M.: On the collocation between dayside auroral activity and coherent HF radar backscatter, Ann. Geophysicae, 18, 1531, 2001.

Moen, J., Walker, I. K., Kersley, L., and Milan, S. E.: On the generation of cusp HF-backscatter irregularities, J. Geophys. Res., 107 (A4), 1044, doi:10.1029/2001JA000111, 2002.

Newell, P. T. and Meng, C.-I.: Ion acceleration at the equatorward edge of the cusp: Low altitude observations of patchy merging, Geophys. Res. Lett., 18, 1829, 1991.

Newell, P. T. and Meng, C.-I.: Cusp low-energy ion cutoffs: A survey and implications for merging, J. Geophys. Res., 100, 21943, 1995.

Newell, P. T. and Meng, C.-I.: Open and closed low latitude boundary layer, in: Polar Cap Boundary Phenomena, edited by Moen, J. et al., p. 91, Kluwer Acad., Norwell, Mass., 1998.

Ogilvie, K. W., Fitzenreiter, R. J., and Scudder, J. D.: Observations of electron beams in the low-latitude boundary layer, J. Geophys. Res., 89, 10723, 1984.

Ogilvie, K. W., Chornay, D. J., Fritzenreiter, R. J., Hunsaker, F. Keller, J., Lobell, J., Miller, G., Scudder, J. D., Sittler, Jr., E. C., Torbert, R. B., Bodet, D., Needell, G., Lazarus, A. J., Steinberg, J. T., Tappan, J. H., Mavretic, A., and Gergin, E.: SWE: A comprehensive plasma instrument for the Wind spacecraft, Space Sci. Rev., 71, 55, 1995.

Oksavik, K., Søraas, F., Moen, J., and Burke, W. J.: Optical and particle signatures of magnetospheric boundary layers near magnetic noon: Satellite and ground-based observations, J. Geophys Res., 105, 27 555, 2000.

Onsager, T. G. and Lockwood, M.: High-latitude particle precipitation and its relationship to magnetospheric source regions, Space Sci. Rev., 80, 77, 1997.

Onsager, T. G., Kletzing, C. A., Ausin, J. B., and MacKiernan, H.: Model of magnetosheath plasma in the magnetosphere: Cusp and mantle particles at low-altitudes, Geophys. Res. Lett., 20, 479, 1993.

Onsager, T. G., Scudder, J. D., Lockwood, M., and Russell, C. T.: Reconnection at the high-latitude mangetopause during northward interplanetary magnetic field conditions, J. Geophys. Res., 106, 25 467, 2001.

Pfaff, R., Clemmons, J., Carlson, C., Ergun, R., McFadden, J., Mozer, F., Temerin, M., Klumpar, D., Peterson, W., Shelley, E., Moebius, E., Kistler, L., Strangeway, R., Elphic, R., and Cattell, C.: Initial FAST observations of acceleration processes in the cusp, Geophys. Res. Lett., 25, 2037, 1998.

Pfaff, R., Carlson, C., Watzin, Everett, J. D., and Gruner, T.: An overview of the Fast Auroral SnapshoT (FAST) satellite, Space. Sci. Rev., 98, 1, 2001.

Ponomarenko, P. V. and Waters, C. L.: The role of Pc1-2 waves in spectral broadening of SuperDARN echoes from high latitudes, Geophys. Res. Lett., 30 (3), 1122, doi:10.1029/2002GL016333, 2003.

Potemra, T. A. and Zanetti, L. J.: Characteristics of large-scale 
Birkeland currents in the cusp and polar regions, in: The Polar Cusp, edited by Holtet, J. A., and Egeland, A., p. 203, D. Reidel Publishing Company, 1985.

Pryse, S. E., Smith, A. M., Kersley, L., and McCrea, I. W.: EISCAT Svalbard radar observations of ionospheric signatures of magnetopause reconnection during a changing IMF $B_{Z}$ polarity, Ann. Geophysicae, 20, 477, 2002.

Rodger, A. S., Mende, S. B., Rosenberg, T. J., and Baker, K. B.: Simultaneous optical and HF radar observations of the ionospheric cusp, Geophys. Res. Lett., 22, 2045, 1995.

Ruohoniemi, J. M., Greenwald, R. A., Baker, K. B., Villain, J. P. and McCready, M. A.: Drift motions of small-scale irregularities in the high-latitude F region: An experimental comparison with plasma drift motions, J. Geophys. Res., 92, 4553, 1987.

Sandholt, P. E., Farrugia, C. J., Moen, J., Noraberg, Ø., Lybekk, B., Sten, T. and Hansen, T.: A classification of dayside auroral forms and activities as a function of interplanetary magnetic field orientation, J. Geophys. Res., 103, 23 325, 1998.

Sauvaud, J.-A., Koperski, P., Beutier, T., Barthe, H., Aoustin, C., Thocaven, J. J., Rouzaud, J., Penou, E., Vaisberg, O., and Borodkova, N.: The INTERBALL-Tail ELECTRON experiment: initial results of the low-latitude boundary layer of the dawn magnetosphere, Ann. Geophysicae, 15, 587, 1997.

Savin, S. P., Balan, O., Borodkova, N., Budnik, E., Nikolaeva, N., Prokhorenko, V., Pulkkinen, T., Rybjeva, N., Safrankova, J., Sandahl, I., Amata, E., Auster, U., Bellucci., G., Blagau, A., Blecki, J., Buechner, J., Ciobanu, M., Dubinin, E., Yermolaev, Yu., Echim, M., Fedorov, A., Formisano, V., Grard, R., Ivchenko, V., Jiricek, F., Juchniewicz, J., Klimov, S., Korepanov, V., Koskinen, H., Kudela, K., Lundin, R., Lutsenko, V., Marghitu, O., Nemecek, Z., Nikutowski, B., Nozdrachev, M., Orsini, S., Parrot, M., Petrukovich, A., Pissarenko, N., Romanov, S., Rauch, J., Rustenbach, J., Sauvaud, J. A., Sarris, E. T., Skalsky, A., Smilauer, J., Triska, P., Trotignon, J. G., Vojta, J., Zastenker, G., Zelenyi, L., Agafonov, Yu., Grushin, V., Khrapchenkov, V., Prech, L., and Santolik, O.: Interball magnetotail boundary case studies, Adv. Space Res., 20, 999, 1997.

Sedgemore-Schulthess, K. J. F., Lockwood, M., Trondsen, T. S., Lanchester, B. S., Rees, M. H., Lorentzen, D. A., and Moen, J.: Coherent EISCAT Svalbard radar spectra from the dayside cusp/cleft and their implications for transient field-aligned currents, J. Geophys. Res., 104, 24 613, 1999.

Sharp, R. D., Shelley, E. G., Johnson, R. G., and Ghielmetti, A. G.: Counterstreaming electron beams at altitudes of $\sim 1 R_{E}$ over the auroral zone, J. Geophys. Res., 85, 92, 1980.

Smith, M. F. and Lockwood, M.: Earth's magnetospheric cusps, Rev. Geophys., 34, 233, 1996.

Stauning, P., Primdahl, F., Watermann, J., and Rasmussen, O.: IMF $B_{y}$-related cusp currents observed from the Ørsted satellite and from ground, Geophys. Res. Lett., 28, 99, 2001.

Su, Y.-J., Ergun, R. E., Peterson, W. K., Onsager, T. G., Pfaff, R., Carlson, C. W., and Strangeway, R. J.: Fast Auroral Snapshot observations of cusp electron and ion structures, J. Geophys. Res., 106, 25 595, 2001.

Su, Y.-J., Ergun, R. E., Jones, S., and Parker, S. E.: Electron accelerations by Alfven waves in the cusp, Geophysical Research Abstracts, Vol. 5, 04 138, European Geophysical Society, 2003.

Takahashi, K., Sibeck, D. G., Newell, P. T., and Spence, H. E.: ULF Waves in the low-latitude boundary layer and their relationship to magnetospheric pulsations: A multisatellite observation, J. Geophys. Res., 96, 9503, 1991.

Trattner, K. J., Fuselier, S. A., Peterson, W. K., Sauvaud, J.-A., Ste- nuit, H., Dubouloz, N., and Kovrazhkin, R. A.: On spatial and temporal structures in the cusp, J. Geophys. Res., 104, 28411 , 1999.

Traver, D. P., Mitchell, D. G., Williams, D. J., Frank, L. A., and Huang, C. Y.: Two encounters with the flank low-latitude boundary layer: Further evidence for closed field topology and investigation of the internal structure, J. Geophys. Res., 96, 21 025, 1991.

Tsunoda, R. T.: High-latitude F-region irregularities: a review and synthesis, Rev. Geophys., 26, 719, 1988

Tsurutani, B. T., Lakhina, G. S., Ho, C. M., Arballo, J. K., Galvan, C., Boonsiriseth, A., Pickett, J. S., Gurnett, D. A., Peterson, W. K., and Thorne, R. M.: Broadband plasma waves observed in the polar cap boundary layer: Polar, J. Geophys. Res., 103, 17351 1998.

Valladares, C. E., Alcaydé, D., Rodriguez, J. V., Ruohoniemi, J. M., and van Eyken, A. P.: Observations of plasma density structures in association with the passage of traveling convection vortices and the occurrence of large plasma jets, Ann. Geophysicae, 17, 1020, 1999.

Villain, J. P., Caudal, G., and Hanuise, C.: A SAFARI-EISCAT comparison between the velocity of $\mathrm{F}$ region small-scale irregularities and the ion drift, J. Geophys. Res., 90, 8433, 1985.

Walker, I. K., Moen, J., Mitchell, C. N., Kersley, L., and Sandholt, P. E.: Ionospheric effects of magnetopause reconnection observed using ionospheric tomography, Geophys. Res. Lett., 25 , 293, 1998

Watermann, J., Lummerzheim, D., de la Beaujardiére, O., Newell, P. T., and Rich, F. J.: Ionospheric footprint of magnetosheathlike particle precipitation observed by an incoherent scatter radar, J. Geophys. Res., 99, 3855, 1994.

Weimer, D. R., Goertz, C. K., Gurnett, D. A., Maynard, N. C., and Burch, J. L.: Auroral zone electric fields from DE 1 and 2 at magnetic conjunctions, J. Geophys. Res., 90, 7479, 1985.

Woch, J., Yamauchi, M., Lundin, R., Potemra, T. A., and Zanetti, L. J.: The low-latitude boundary layer at mid-altitudes: Relation to large-scale Birkeland currents, Geophys. Res. Lett., 20, 2251 , 1993.

Yamauchi, M., Lundin, R., Eliasson, L., Ohtani, S., and Clemmons, J. H.: Relationship between large-, meso-, and small-scale fieldaligned currents and their current carriers, in: Polar Cap Boundary Phenomena, edited by Moen, J. et al., p. 173, Kluwer Acad., Norwell, Mass., 1998.

Yeoman, T. K., Lester, M., Cowley, S. W. H., Milan, S. E., Moen, J., and Sandholt, P. E.: Simultaneous observations of the cusp in optical, DMSP and HF radar data, Geophys. Res. Lett., 24, 2251, 1997.

Yeoman, T. K., Wright, D. M., Stocker, A. J., Jones, T. B.: An evaluation of range accuracy in the Super Dual Auroral Radar Network over-the-horizon HF radar systems, Radio Sci., 36, 801, 2001.

Yeoman, T. K., Hanlon, P. G., and McWilliams, K. A.: A statistical study of the location and motion of the HF radar cusp, Ann. Geophysicae, 20, 275, 2002.

Yoshioka, R., Miyake, W., Mukai, T., and Ito, M.: Field-aligned electron beams observed simultaneously with upflowing ion beams in the auroral acceleration region, J. Geophys. Res., 105, 7679, 2000.

Zanetti, L. J., Potemra, T. A., Doering, J. P., Lee, J. S., and Hoffman, R. A.: Magnetic field-aligned electron distributions in the dayside cusp, J. Geophys. Res., 86, 8957, 1981. 